\title{
Article \\ SEM Evaluation of Endosequence BC Sealer Hiflow in Different Environmental Conditions
}

\author{
Orlando Donfrancesco ${ }^{1,2}$, Andrea Del Giudice ${ }^{2}$, Alessio Zanza ${ }^{2}$ D , Michela Relucenti ${ }^{1}$ (D), Stefano Petracchiola ${ }^{2}$, \\ Gianluca Gambarini ${ }^{2}$, Luca Testarelli ${ }^{2, *}$ (D) and Marco Seracchiani ${ }^{2}$
}

1 Department of Anatomy, Histology, Forensic Medicine and Orthopaedics, Sapienza University of Rome, 00185 Rome, Italy; orlando.donfrancesco@uniroma1.it (O.D.); michela.relucenti@uniroma1.it (M.R.)

2 Department of Oral and Maxillo Facial Sciences, Sapienza University of Rome, 00161 Rome, Italy; andrea.delgiudice@uniroma1.it (A.D.G.); ale.zanza@gmail.com (A.Z.); stefanopetracchiola@gmail.com (S.P.); Gianluca.gambarini@uniroma1.it (G.G.); marco.seracchiani@uniroma1.it (M.S.)

* Correspondence: luca.testarelli@uniroma1.it

\section{check for}

updates

Citation: Donfrancesco, O.; Del Giudice, A.; Zanza, A.; Relucenti, M.; Petracchiola, S.; Gambarini, G.; Testarelli, L.; Seracchiani, M. SEM Evaluation of Endosequence BC Sealer Hiflow in Different Environmental Conditions. J. Compos. Sci. 2021, 5, 99. https://doi.org/ $10.3390 /$ jcs5040099

Academic Editor:

Francesco Tornabene

Received: 29 March 2021

Accepted: 2 April 2021

Published: 4 April 2021

Publisher's Note: MDPI stays neutral with regard to jurisdictional claims in published maps and institutional affiliations.

Copyright: (C) 2021 by the authors Licensee MDPI, Basel, Switzerland. This article is an open access article distributed under the terms and conditions of the Creative Commons Attribution (CC BY) license (https:// creativecommons.org/licenses/by/ $4.0 /)$.
Abstract: The aim of the present study is to evaluate the setting and sealant ability of two different bioceramic sealers in two different environmental conditions: humid and wet environment. Ex vivo root canal treatment was performed on 24 freshly extracted teeth. Irrigation was performed with Niclor $\mathrm{NaOCl} 5 \%$ and EDTA 17\%, then obturated with a bioceramic sealer in the two different environmental conditions listed above. Furthermore, scanning electron microscope (SEM) investigation was performed to verify the presence of gaps and the setting ability of the two sealers in two different environmental conditions was evaluated. While presence of gaps was found mainly in the wet specimens, on the other hand, regarding the setting ability, there is no statistically significant difference between the two different samples. Therefore, even if humid conditions represent the gold standard in terms of lower gaps dimension, since there is no methodology standardizing the drying procedure of the root canal, it is compulsory to investigate the sealing ability of the bioceramic sealers, even in wet conditions. Thanks to the findings shown in the present study, it is demonstrated that even in wet conditions the ability of the sealer to set does not change and such clinical situation could affect the bioceramic sealer protocol.

Keywords: bioceramic; endodontics; BC sealer

\section{Introduction}

Bioceramic materials have been introduced in medicine since the middle of the 1960s, and their use spread rapidly in orthopedic surgery, as bone substitutes. They have peculiar characteristics such as biocompatibility, absence of metallic components and inorganic nature [1]. Bioceramics can be divided based to their bio-activity:

- $\quad$ Bio-inert, do not interact with tissues.

- Bio-active, interact tissues without creating adverse reactions (osteoinductive and osteoconductive);

- Bio-degradable, absorbable with new bone formation.

In dentistry, the first biomaterial introduced on the marketplace was the MTA (mineral trioxid aggregate). It was mainly used as root repair material (RRM), to close perforation and apicoectomy, for apexification and pulp capping [2].

Moreover, it has been proven that the improved characteristics of bioceramics-such as high biocompatibility, not absorbable, high antibacterial properties, and adhesion to dentin walls-were the exact characteristics of an ideal sealer [3]. Therefore, in the past decade, bioceramic materials have been proposed as endodontic sealers and not only as root repair material. Therefore, bioceramic sealer compositions are based on tricalcium and bicalcium silicate. This is indeed the component which determines the capability 
of these sealers to reinforce the dentin walls, lowering the fracture rate after root canal treatments [4].

The introduction of bioceramic sealers, thanks to the absence of absorbability, has changed the paradigm of root canal filling. Indeed, up to now, the root canal was filled using guttapercha (GP) cones and the endodontic sealer was used just to fill the gap between GP and dentin walls. Instead, with the introduction of bioceramic sealers, the endodontic filling is performed using these materials, and the use of GP cones has the twofold function of vehiculate the sealer to the apex and to maintain a space to eventually retreat the tooth. Leaving a proper space to eventually retreat the canal would also soften the torsional load over the rotary instruments [5]. It has indeed been analyzed by Ayhan Eymirli et al. the possibility to retreat a tooth sealed with bioceramics using different GP diameters [6]. The study showed an easier approach for the root canals sealed with 04 cones rather than 02 .

The prognosis of teeth treated with bioceramic sealers has proven to be highly accommodating due to their specific biocompatibility and bioactivity. However, to date, there are few studies that evaluate the long-term outcome of these sealers, due to their recent introduction in the marketplace. Chybowski, Elizabeth A. et al. provided a $90.6 \%$ of success, which rises at $91.7 \%$ after retreatment. These results were compared to other studies analyzing the outcome of RCTs using zinc-oxide-eugenol sealers, such as "The Toronto Study", showing a slightly difference in favor of bioceramic sealers $(90.6 \%$ and $91.7 \%$ against $89.1 \%$ and $85.6 \%$ ) [7].

Despite the high success percentage of bioceramic sealers filling, the application protocol is still uncertain [8]. Indeed, according to manufacturer instructions, the root canal should be humid. On the other hand, anew according to the above-mentioned instructions, the bioceramic sealer will not set if the root canal is wet. To obtain this, some authors suggest performing the drying procedure with just one paper point chosen accordingly to the last instrument used. Anyway, this technique has a high variability depending on the root canal morphology [9], that could lead to different degrees of humidity due to the unpredictability of narrow root canals [10,11]. After a proper irrigation [12], root canal obturation has a prominent role regarding the long-term success of a root canal treatment and therefore the above-mentioned variability cannot be accepted with the nowadays standards of quality required in endodontics. Therefore, the present study aims to evaluate the setting and the sealant ability of bioceramic sealers using two different methods. Precisely modifying the humidity conditions of the endodontic system to compare the above-mentioned characteristics in humid and wet root canal space.

\section{Materials and Methods}

A total of 24 freshly extracted teeth has been selected for the present study. Teeth were extracted for periodontal or orthodontic reasons and were stored in saline solution $0.9 \%$ for maximum $24 \mathrm{~h}$ before being used for the tests. Were excluded from the study teeth already treated endodontically, teeth with signs of external or internal resorption, teeth with more than one canal, and teeth with only one canal with a curvature higher than $20^{\circ}$, according to Pruett's method [13]. This method measures both the angle and the radius of curvature using a combination of two straight lines and a circular arc. Pruett's method is geometrically equivalent to Weine's method [14] regarding the measurement of the angle, however its major innovation was the measurement of the radius of curvature by the superimposition of an arc on the curved portion of the root canal.

To confirm the adherence to the above-mentioned criteria, all teeth underwent cone beam computed tomography (CBCT) before being used for the tests [15].

\subsection{Sample Preparation}

\subsubsection{Root Canal Mechanical-Antiseptic Preparation}

The access cavity was performed under copious irrigation with a stainless-steel bur mounted on a high-speed handpiece [16]. The working length was visually determined 
by introducing a K-file instrument into the root canal (ISO MM ${ }^{\circledR}$ diameter 10/100 mm), until the tip was visible at the apex. The working length was determined by withdrawing the instrument for $0.5 \mathrm{~mm}$. All teeth were instrumented by a single operator up to $25.07 \mathrm{v}$ using the whole EdgeTaper Platinum (EdgeEndo, Albuquerque, NM, USA) sequence up to the F2 instrument. The instrumentation has been performed using Eighteeth Connect Endodontic Motor (Eighteeth, Shangai, China) [17]. During the whole instrumentation, the canal has been irrigated with Niclor $\mathrm{NaOCl} 5 \%$ (Ogna, Padua, Italy) in order to disinfect and dissolve the pulp. At the end of the preparation, the root canal was irrigated with $2 \mathrm{~mL}$ EDTA 17\% concentration, maintained for $3 \mathrm{~min}$ in order to remove the smear layer.

\subsubsection{Root Canal Obturation}

At this point, the 24 samples were randomly divided in two groups of 12 each (group $A$ and $B$ ), group $A$ underwent the traditional drying procedure, which is carried out by the use of paper points, while Group B did not undergo the drying procedure. The obturation technique proposed for both groups was the same and it was carried out as follows: sealer insertion up to half of the working length, a dedicated gutta-percha cone covered with a minimum amount of sealer and inserted up to 0.5 to the working length, finally the coronal part of the gutta-percha cone has been cut using a heat carrier. Afterwards, the samples have been stored in a humid incubator at $37^{\circ} \mathrm{C}$ for 28 days, to allow the setting time of the material. After the complete setting of the sealers, the samples were placed in distilled water for $10 \mathrm{~min}$, rinsed with absolute ethanol for $15 \mathrm{~min}$ and then placed in an oven at a constant temperature of $37^{\circ} \mathrm{C}$ for $24 \mathrm{~h}$ in order to dry them. The samples have been sectioned longitudinally using a bur mounted on an highspeed handpiece.

\subsubsection{Setting Analysis}

Before immerging the samples in distilled water for $10 \mathrm{~min}$, as stated in the above paragraph, all samples were tested to verify the sealer setting ability in the two different environments. This test was carried out by using a custom device able to apply a standardized pression of $400 \mathrm{~g}$ using a $6 \mu \mathrm{m}$ needle. This needle is represented by the $06 \mathrm{k}$-file which indeed presents a tip diameter of $6 \mu \mathrm{m}$.

\subsection{SEM Evaluation}

Afterwards, samples have been observed using a variable pressure scanning electron microscope, VP-SEM, (SU3550, Hitachi High Technologies Corporation, Tokyo, Japan) [18]. The SEM investigation was carried out in order to identify the presence of absence of gaps between the sealer and the dentinal walls of the root canal. The present investigation focused on the individuation of gaps at $3 \mathrm{~mm}$ and at $1 \mathrm{~mm}$ from the apex for humid samples and for wet samples. In Figure 1, four SEM pictures showing gaps in humid samples.

On the other hand, regarding the wet specimens, other SEM pictures were taken to compare the gaps formation in different environmental conditions as shown in Figure 2.

Moreover, once these gaps are identified, a dedicated software (ImageJ) was used to evaluate the gap dimensions between the sealer and the dentinal walls.

Data were recorded and analyzed using IBM SPSS statistics software version 22.0. Moreover, Mann-Whitney $\mathrm{U}$ test $(p<0.05)$ was performed comparing respectively the samples at $1 \mathrm{~mm}$ and at $3 \mathrm{~mm}$ for both the different environmental conditions. It has been decided to use a non-parametric statistical test to run the statistical investigation due to the fact that the preliminary evaluation of the samples did not demonstrate a norma distribution. 


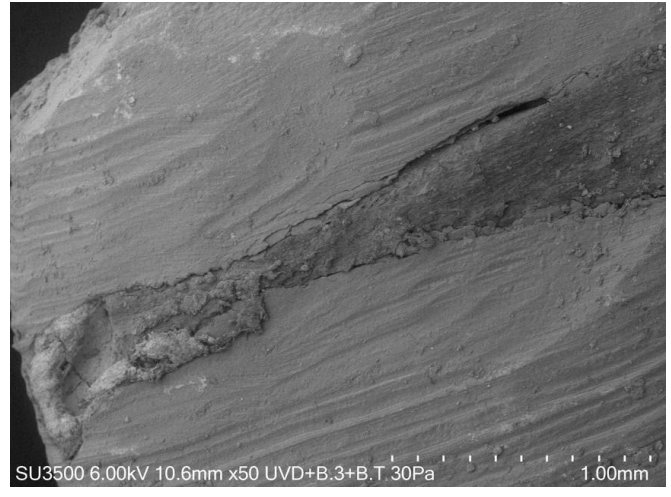

(a)

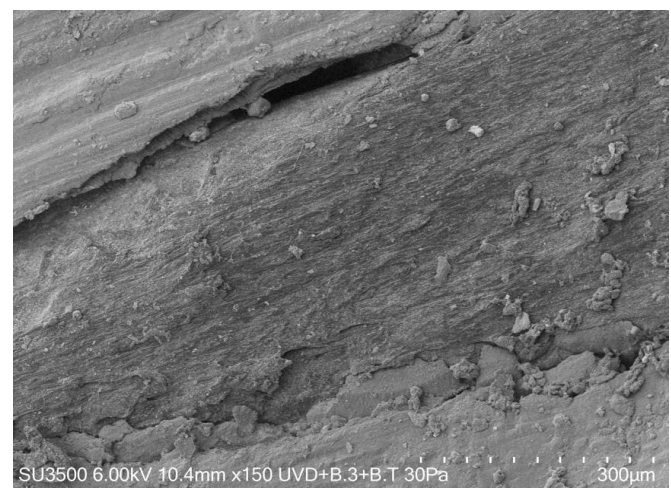

(c)

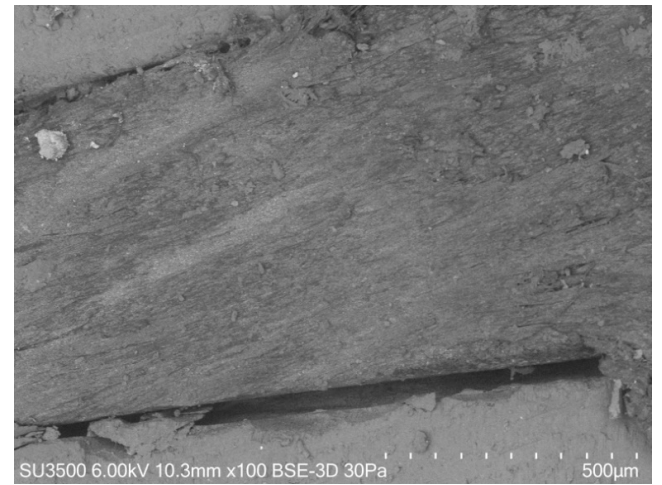

(b)

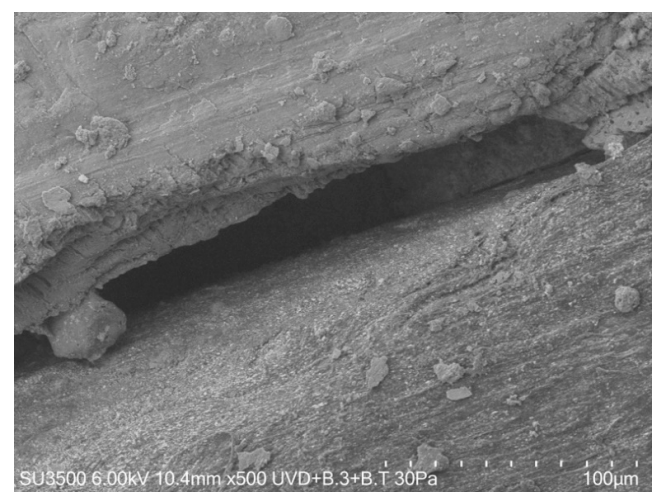

(d)

Figure 1. Gap observation of humid samples at four different magnifications. (a) $1 \mathrm{~mm}$; (b) $500 \mu \mathrm{m}$; (c) $300 \mu \mathrm{m}$; (d) $100 \mu \mathrm{m}$.

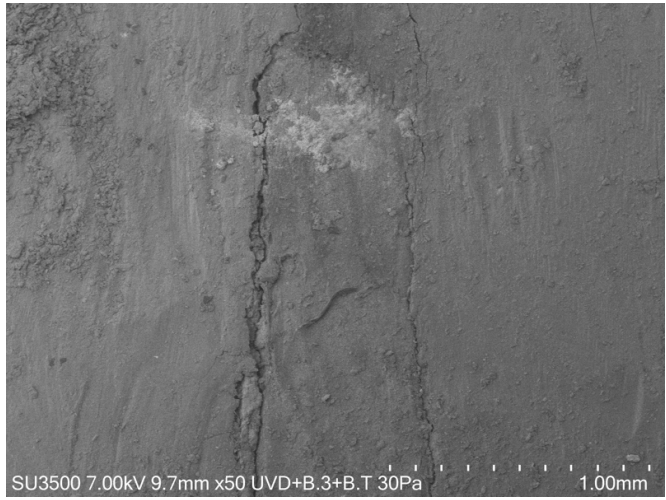

(a)

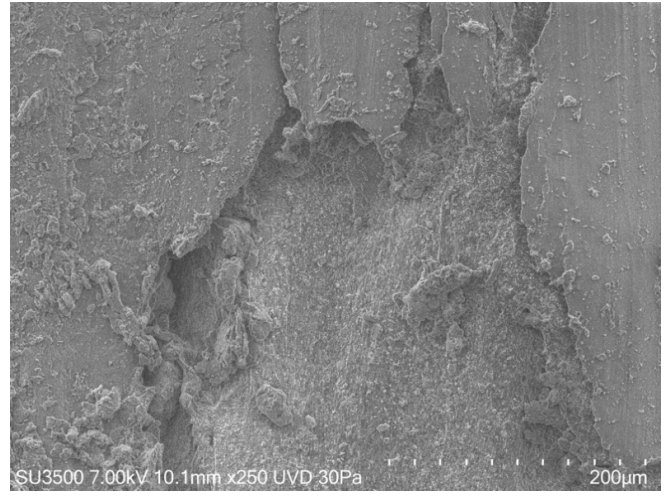

(c)

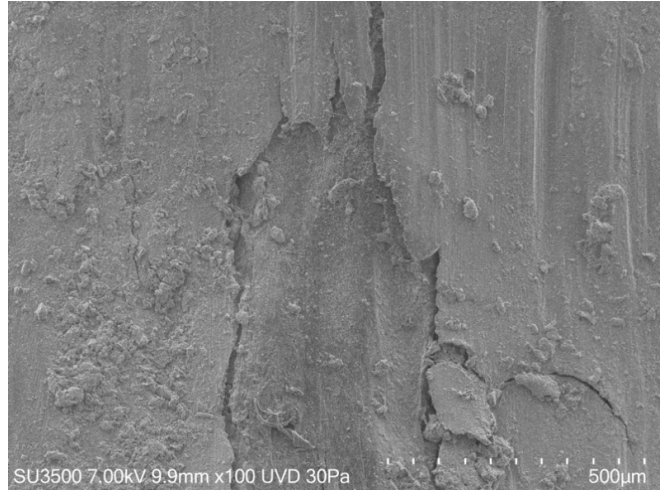

(b)

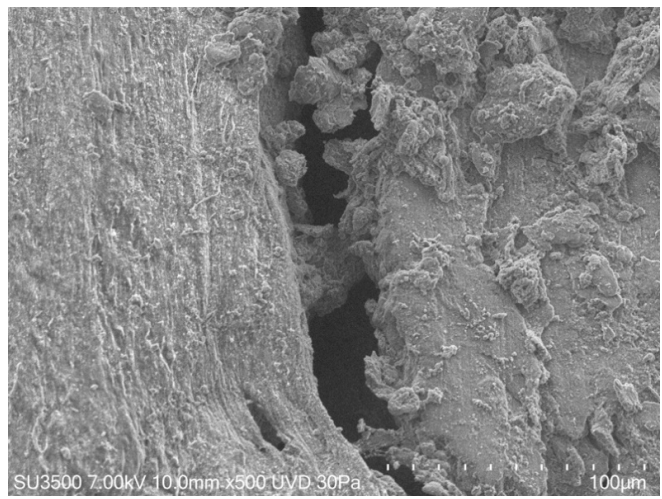

(d)

Figure 2. Gap observation of wet samples at four different magnifications. (a) $1 \mathrm{~mm}$; (b) $500 \mu \mathrm{m}$; (c) $300 \mu \mathrm{m}$; (d) $100 \mu \mathrm{m}$. 


\section{Results}

Setting ability of both EndoSequence BC sealer and Endosequence Hiflow specimens were evaluated using the test mentioned in the Section 2.1.3 of the manuscript [8]. The mean gap value of humid teeth, $5.81 \mu \mathrm{m}$, was lower than the mean gap of wet teeth, $9.46 \mu \mathrm{m}$. The difference was statistically relevant $(p<0.05)$. The mean gap value comparison at $3 \mathrm{~mm}$ from the apex was not statistically different between the two groups $(p>0.05)$, while the values $1 \mathrm{~mm}$ from the apex were statistically relevant $(p<0.05)$, showing a significative difference between the two samples: $6.836 \mu \mathrm{m}$ for humid sample and $13.326 \mu \mathrm{m}$ for wet sample. The values are reported in Table 1 for $1 \mathrm{~mm}$ measurement and Table 2 for the $3 \mathrm{~mm}$ measurement.

Table 1. Gap measurements at $1 \mathrm{~mm}$ between dentinal wall and bioceramic sealer $(\mu \mathrm{m})$.

\begin{tabular}{ccc}
\hline Measurement & Humid Environment & Wet Environment \\
\hline $\mathbf{1}$ & 7.843 & 14.272 \\
$\mathbf{2}$ & 14.505 & 13.187 \\
$\mathbf{3}$ & 19.042 & 9.963 \\
$\mathbf{4}$ & 1.614 & 9.528 \\
$\mathbf{5}$ & 2.641 & 7.149 \\
$\mathbf{6}$ & 4.117 & 26.168 \\
$\mathbf{7}$ & 4.758 & 20.964 \\
$\mathbf{8}$ & 4.95 & 11.955 \\
$\mathbf{9}$ & 5.322 & 10.448 \\
$\mathbf{1 0}$ & 7.113 & 11.049 \\
$\mathbf{1 1}$ & 5.243 & 11.359 \\
$\mathbf{1 2}$ & 7.548 & 12.206 \\
Mean & 6.836 & 13.326 \\
SD & 5.024 & 5.288 \\
\hline
\end{tabular}

Table 2. Gap measurements at $3 \mathrm{~mm}$ between dentinal wall and bioceramic sealer $(\mu \mathrm{m})$.

\begin{tabular}{ccc}
\hline Measurement & Humid Environment & Wet Environment \\
\hline $\mathbf{1}$ & 3.638 & 2.388 \\
$\mathbf{2}$ & 4.63 & 3.875 \\
$\mathbf{3}$ & 9.468 & 2.691 \\
$\mathbf{4}$ & 7.057 & 3.61 \\
$\mathbf{5}$ & 3.884 & 6.381 \\
$\mathbf{6}$ & 2.111 & 4.464 \\
$\mathbf{7}$ & 2.273 & 2.267 \\
$\mathbf{8}$ & 5.277 & 1.786 \\
$\mathbf{9}$ & 3.983 & 17.057 \\
$\mathbf{1 0}$ & 7.881 & 7.761 \\
$\mathbf{1 1}$ & 3.823 & 9.273 \\
$\mathbf{1 2}$ & 3.481 & 5.672 \\
Mean & 4.792 & 5.602 \\
SD & 2.252 & 4.293 \\
\hline
\end{tabular}

\section{Discussion}

Endosequence BC Sealer (Brasseler, Savannah, GA, USA) is one of the most used bioceramic sealers around the world. It is a premixed and injectable sealer based on a tricalcium silicate matrix. According to manufacturer instruction, the polymerization reaction of this sealer is induced by physiological humidity of the dentin tubules. This reaction allows a chemical bond to dentin and an expansion of the materials inside the root canal, improving therefore its sealing ability. The setting time should be about $4 \mathrm{~h}$; however, according to the humidity conditions the setting time can also reach $10 \mathrm{~h}$. According to manufacturer instructions, setting could not be reached in wet condition. The maximum expansion will be obtained in 28 days [19]. 
In the present studies a variant of the Endosequence BC Sealer has been used, the Endosequence HiFlow. This sealer has the same composition of the above-mentioned endodontic sealer, except for a higher percentage of Zirconium dioxide and a lower percentage of calcium ions. This modifies the radio opacity of the material [20]. This material was thought to be used also for hot filling technique. Despite that, according to a recent study performed at $37^{\circ} \mathrm{C}$ and at $100{ }^{\circ} \mathrm{C}$, the HiFlow has a comparable setting time, micro-hardness and solubility, but a higher flowability than Endosequence BC Sealer. This improvement increases the sealing ability, allowing better penetration and filling of irregularities of the root canal, also in cold filling technique.

This is the first study to evaluate the setting of Endosequence BC Sealer HiFlow in wet condition. The results of the present study demonstrate that the setting can be reached without any signs of difference with both the proposed techniques, differently from what reported by the present literature [21,22]. This result could dispel doubts about the setting of Endosequence BC Sealer HiFlow and to overcome the issues due to not controllable humidity conditions. Furthermore, according to the above mentioned studies, these two sealers, modifying the endodontic environment, should present a different sealant ability. However, the present study evaluated the sealing ability of these two bioceramic sealers either in wet or in humid conditions. This evaluation has been carried out due to the fact that there is no standardized methodology that allows the clinician to know whether the canal is humid or wet. Therefore, due to this main difficulty it has been decided to analyze the differences between a sealer in humid or wet conditions regarding setting ability and presence/absence of gaps. Moreover, the present study focused on the analysis of the setting ability of these two different bioceramic sealers. This is clearly a clinically relevant observation due to the fact that firstly, there is no standardized method to reach a reproducible intracanal 'humid environment' and secondly because once the obturation has been carried out, even in wet conditions, the clinician has to be sure that the bioceramic sealer will eventually set. This result highlights the reliability of these biocaramic sealers as a proper filling material, regardless the environmental conditions in which they are used.

From the results of the present study, no significant difference has been found at $3 \mathrm{~mm}$ from the apex. While, larger gaps between the sealer and the root canal walls were found in the last millimeter of the apical third of the wet samples. These gaps, displayed in Figure 1 with different magnifications, have been spotted thanks to SEM evaluation [23,24]. This finding can be explained by the fact that the water molecules gather up in the last apical millimeter and therefore block the sealer progression towards the dentinal walls.

Up to date literature agrees on the fact that wet conditions of the canal would interfere with the setting ability of the sealer [21,22]. Therefore, it would be logical to expect from the results of the present study to identify flawed samples regarding sealant hardness as well. However, the wet samples showed no significant difference regarding the polymerization process if confronted to the humid ones. Indeed, from the setting evaluation of the samples the two different sealers seem to be properly hardened: negative indentation test performed with $6 \mu \mathrm{m}$ needles demonstrates the correct sealers setting. This finding is in opposition to the current literature and therefore the present study is successfully revealing a peculiar behavior from the sealer. Indeed, the sealer was expected not to endure due to the presence of water molecules but thanks to the results of the present study such statement should not be considered valid anymore.

\section{Conclusions}

This evaluation allows the present study to state that the main difference between humid and wet conditions of the root canal interfere only with the gap formation in the last apical millimeter; however, it has been demonstrated that it does not affect the setting process of the sealant. Moreover, if these results affect the outcome of the root canal treatment should be the subject of further studies. As stated in the above mentioned articles [21,22], humid conditions make the sealant able to better perform root canal sealing but since there is no standardized method to reach and properly verify this environmental 
condition, it is compulsory to study the possible outcomes of wet conditions as well. Although it is auspicable to seal a canal with a bioceramic sealer in humid conditions, from the results of the present study it has been demonstrated that a sealing in wet conditions could grant a stable seal as well.

Author Contributions: Formal analysis, A.Z. and G.G.; Project administration, L.T.; Software, M.R. and S.P.; Visualization, O.D.; Writing-Original draft, A.D.G.; Writing-Review \& editing, M.S. All authors have read and agreed to the published version of the manuscript.

Funding: This research received no external funding.

Conflicts of Interest: The authors declare no conflict of interest.

\section{References}

1. Kaur, A.; Shah, N.; Logani, A.; Mishra, N. Biotoxicity of commonly used root canal sealers: A meta-analysis. J. Conserv. Dent. 2015, 18, 83-88.

2. Staffoli, S.; Plotino, G.; Nunez Torrijos, B.G.; Grande, N.M.; Bossù, M.; Gambarini, G.; Polimeni, A. Regenerative Endodontic Procedures Using Contemporary Endodontic Materials. Materials 2019, 19, 12. [CrossRef] [PubMed]

3. Jean, A.; Kerebel, B.; Kerebel, L.-M.; Legeros, R.Z.; Hamel, H. Effects of various calcium phosphate biomaterials on reparative dentin bridge formation. J. Endod. 1988, 14, 83-87. [CrossRef]

4. Pissiotis, E.; Spngberg, L.S.W. Biological evaluation of collagen gels containing calcium hydroxide and hydroxyapatite. J. Endod. 1990, 16, 468-473. [CrossRef]

5. Gambarini, G.; Seracchiani, M.; Zanza, A.; Miccoli, G.; Del Giudice, A.; Testarelli, L. Influence of shaft length on torsional behavior of endodontic nickel-titanium instruments. Odontology 2020. [CrossRef] [PubMed]

6. Eymirli, A.; Sungur, D.D.; Uyanik, O.; Purali, N.; Nagas, E.; Cehreli, Z.C. Dentinal Tubule Penetration and Retreatability of a Calcium Silicate-based Sealer Tested in Bulk or with Different Main Core Material. J. Endod. 2019, 45, 1036-1040. [CrossRef]

7. Chybowski, E.A.; Glickman, G.N.; Patel, Y.; Fleury, A.; Solomon, E.; He, J. Clinical Outcome of Non-Surgical Root Canal Treatment Using a Single-cone Technique with Endosequence Bioceramic Sealer: A Retrospective Analysis. J. Endod. 2018, 44, 941-945. [CrossRef] [PubMed]

8. Loushine, B.A.; Bryan, T.E.; Looney, S.W.; Gillen, B.M.; Loushine, R.J.; Weller, R.N.; Pashley, D.H.; Tay, F.R. Setting properties and cytotoxicity evaluation of a premixed bioceramic root canal sealer. J. Endod. 2011, 37, 5. [CrossRef]

9. Miccoli, G.; Seracchiani, M.; Del Giudice, A.; Mazzoni, A.; D'Angelo, M.; Bhandi, S.; Gambarini, G.; Testarelli, L. Fatigue Resistance of Two Nickel-Titanium Rotary Instruments before and after Ex Vivo Root Canal Treatment. J. Contemp Dent. Pract. 2020, 21, 728-732.

10. Di Nardo, D.; Seracchiani, M.; Mazzoni, A.; Del Giudice, A.; Gambarini, G.; Testarelli, L. Torque Range, a New Parameter to Evaluate New and Used Instrument Safety. Appl. Sci. 2020, 10, 3418. [CrossRef]

11. Gambarini, G.; Miccoli, G.; Di Nardo, D.; Del Giudice, A.; Mazzoni, A.; Seracchiani, M.; Testarelli, L. Torsional resistance of two new heat treated nickel titanium rotary instruments: An in vitro evaluation. Pesqui. Bras. Odontopediatria Clin. Integr. 2020, 20, 1-7. [CrossRef]

12. Mazzoni, A.; Pacifici, A.; Zanza, A.; Giudice, A.D.; Reda, R.; Testarelli, L.; Gambarini, G.; Pacifici, L. Assessment of Real-Time Operative Torque during Nickel-Titanium Instrumentation with Different Lubricants. Appl. Sci. 2020, 10, 6201. [CrossRef]

13. Faraj, S.; Boutsioukis, C. Observer variation in the assessment of root canal curvature. Int. Endod. J. 2017, 50, 167-176. [CrossRef]

14. Günday, M.; Sazak, H.; Garip, Y. A comparative study of three different root canal curvature measurement techniques and measuring the canal access angle in curved canals. J. Endod. 2005, 31, 796-798. [CrossRef] [PubMed]

15. Valenti-Obino, F.; Di Nardo, D.; Quero, L.; Miccoli, G.; Gambarini, G.; Testarelli, L.; Galli, M. Symmetry of root and root canal morphology of mandibular incisors: A cone-beam computed tomography study in vivo. J. Clin. Exp. Dent. 2019, 11, 527-533. [CrossRef] [PubMed]

16. Miccoli, G.; Cicconetti, A.; Gambarini, G.; Giudice, A.D.; Ripanti, F.; Di Nardo, D.; Testarelli, L.; Seracchiani, M. A new device to test the bending resistance of mechanical endodontic instruments. Appl. Sci. 2020, 10, 7215. [CrossRef]

17. Di Nardo, D.; Gambarini, G.; Seracchiani, M.; Mazzoni, A.; Zanza, A.; Giudice, A.D.; D’Angelo, M.; Testarelli, L. Influence of different cross-section on cyclic fatigue resistance of two nickel-titanium rotary instruments with same heat treatment: An in vitro study. Saudi Endod. J. 2020, 10, 221-225.

18. Grimaldi, A.; Serpe, C.; Chece, G.; Nigro, V.; Sarra, A.; Ruzicka, B.; Relucenti, M.; Familiari, G.; Ruocco, G.; Pascucci, G.R.; et al. Microglia-Derived Microvesicles Affect Microglia Phenotype in Glioma. Front. Cell. Neurosci. 2019, 13, 41. [CrossRef]

19. Donfrancesco, O.; Seracchiani, M.; Morese, A.; Ferri, V.; Nottola, S.A.; Relucenti, M.; Gambarini, G.; Testarelli, L. Analysis of Stability in Time of Marginal Adaptation of Endosequence Root Repair Material on Biological Samples. Dent. Hypotheses 2020, 11, 11-15.

20. Gambarini, G.; Plotino, G.; Grande, N.M.; Testarelli, L.; Prencipe, M.; Messineo, D.; Fratini, L.; D'Ambrosio, F. Differential diagnosis of endodontic-related inferior alveolar nerve paraesthesia with cone beam computed tomography: A case report. Int. Endod. J. 2011, 44, 176-181. [CrossRef] 
21. Gandolfi, M.G.; Iacono, F.; Agee, K.; Siboni, F.; Tay, F.; Pashley, D.H.; Prati, C. Setting time and expansion in different soaking media of experimental accelerated calcium-silicate cements and ProRoot MTA. Oral. Surg. Oral. Med. Oral. Pathol. Oral. Radiol. Endod. 2009, 108, e39-e45. [CrossRef] [PubMed]

22. Chen, B.; Haapasalo, M.; Mobuchon, C.; Li, X.; Ma, J.; Shen, Y. Cytotoxicity and the Effect of Temperature on Physical Properties and Chemical Composition of a New Calcium Silicate-based Root Canal Sealer. J. Endod. 2020, 46, 531-538. [CrossRef] [PubMed]

23. Bossù, M.; Saccucci, M.; Salucci, A.; Di Giorgio, G.; Bruni, E.; Uccelletti, D.; Sarto, M.S.; Familiari, G.; Relucenti, M.; Polimeni, A. Enamel remineralization and repair results of Biomimetic Hydroxyapatite toothpaste on deciduous teeth: An effective option to fluoride toothpaste. J. Nanobiotechnol. 2019, 17, 17. [CrossRef] [PubMed]

24. Relucenti, M.; Miglietta, S.; Bove, G.; Donfrancesco, O.; Battaglione, E.; Familiari, P.; Barbaranelli, C.; Covelli, E.; Barbara, M.; Familiari, G. SEM BSE 3D Image Analysis of Human Incus Bone Affected by Cholesteatoma Ascribes to Osteoclasts the Bone Erosion and VpSEM dEDX Analysis Reveals New Bone Formation. Scanning 2020, 2020, 9371516. [CrossRef] [PubMed] 